\title{
Sexual Abuse - Current Medico-legal, Forensic and Psychiatric Aspects
}

\author{
R. Nardello, A. Compagno, A. Argo, S. Zerbo, P. Procaccianti, \\ and S. Mangano
}

\begin{abstract}
Violence against women and minors is a worldwide problem that has not yet been sufficiently acknowledged. There are many obstacles especially when sexual abuses have to be evaluated. These problems are present both when victims of sexual abuse are evaluated and when sex offenders are dealt with, especially when the offenders are juvenile sex offenders (JSO).

These issues give cause for great concern about prognosis, and the resulting psychosocial implications, and call for a special effort from the scientific community in identifying appropriate prevention and treatment methods.

This chapter is divided into two parts. The first part deals with the forensic and psychiatric features, such as diagnostic and therapeutic/rehabilitative strategies for JSO, while the second part analyzes the legal-medicine aspects related to rape/sexual assault in a European context.
\end{abstract}

R. Nardello $(\bowtie) \cdot S$. Mangano

Dipartimento di Scienze per la Promozione della Salute e Materno Infantile "G. D'Alessandro", Unità Operativa di Neuropsichiatria Infantile, Università degli Studi di Palermo, Palermo, Italy e-mail: r.nardello@unipa.it; manganos@katamail.com
A. Compagno
Servizio per l'età evolutiva - U.O.C. Infanzia Adolescenza e Famiglia, Azienda ULSS7 Veneto, Pieve di Soligo, Italy
e-mail: adricompagno@libero.it
A. Argo $\bullet$ S. Zerbo $\bullet$ P. Procaccianti
Dipartimento di Biopatologia e Biotecnologie Mediche e Forensi, Università degli Studi di Palermo, Palermo, Italy
e-mail: antonella.argo@libero.it; stefaniazerbo@virgilio.it; paolo.procaccianti@unipa.it 


\section{Introduction}

There are two protagonists in the event of a sexual abuse: the offender and the abuse victim. Several forensic, medicolegal, and clinical implications involve this issue, especially if the offender and the abuse victim are both minors. Many etiological hypotheses have been proposed about the origin of adolescent sex offending, but none of them could be considered exhaustive. A multifactorial etiopathogenetic background seems to be very likely. Genetic/hereditary and environmental factors are strictly interwoven, and a large number of character/temperament configurations - as well as possible psychological/psychiatric disturbances - are surely involved. Diagnosis and treatment of sex offenses perpetrated by youngsters are strongly influenced by multiple, interactive etiopathogenetic factors, and the same goes for the numerous attempts to provide a comprehensive nosological classification of adolescents who have committed sex offenses.

The other side of the coin is the abuse victim. Several medical, psychological, social, and juridical aspects are involved in the identification, diagnosis, management, and treatment of the victims who have suffered sexual abuse, and a multidisciplinary approach is always required. An accurate anatomical-clinical knowledge cannot be separated by specific forensic medicine skills, and laboratory tests and other instrumental investigations, as well as a detailed analysis of the environmental context, must be often carried out together with the physical examination of the victim. In the cases of physical examination results being totally negative, the testimony of the minor becomes extremely important, as it could be the only evidence of the existence of a crime. This entails a large number of risks, first of all for the minor presumed abuse victim, although the certainty or not of the abuse itself. This is the reason why some guidelines to examine the minor in the event of sexual abuse have been developed, of which the Italian Noto Charter, drafted for the first time in 1996 and reviewed in 2002, is a typical example. This document defines roles and responsibilities of the "expert," as well as of the judge, and specifies measures to safeguard the minor from possible psychological and emotional sequalae.

A double-sided point of view - from adolescent sex offender and from children victim of sex abuse - is the only strategy to deal with the complex and problematic issue of juvenile sex offenses.

\section{Part I: Diagnostic and Therapeutic/Rehabilitative Strategies for Juvenile Sex Offenders}

\section{Etiology and Classification of Juvenile Sex Offenses}

Sexual offenses perpetrated by youngsters are becoming much more frequent than in the past. It has been estimated that about $20 \%$ of all rapes and about $50 \%$ of child abuses are committed by juvenile sex offenders (JSO) [1]. It seems that a high percentage of the JSO are between the ages of 12 and 15 . 
To enhance a good grasp of the problem, it could be advisable to consider briefly the main theories about etiology of adolescent sex offending and the most useful of the several classification systems of JSO for clinical and legal practice.

Many hypotheses have been formulated about the origin of the sex offending behavior. For instance, some authors assumed that personality disorders, such as psychopathy and early traumatizing experiences, have a significant impact on the development of an antisocial and aggressive conduct, which could lead the adolescent to commit sexual offenses among other possible crimes [2].

Distinguishing different types of adolescent offenders, also within the category of youngsters who have committed sexual offenses, Van Wijk and coworkers identified five different groups: (1) violent sex offenders, (2) nonviolent sex offenders, (3) sex offenders against children, (4) violent offenders, and (5) offenders charged with any crime other than interpersonal body contact crimes. Comparing these groups on their phenomenological characteristics and psychiatric diagnoses according to the DSM-IV, the authors discovered a more frequent occurrence of developmental disorders only among nonviolent sex offenders and sex offenders against children [3].

There are also many psychosocial factors that need to be displayed. For example, by analyzing the differences in self-reports among three groups of JSO, distinguished on the basis of the risk of committing sex offenses, Smith et al. discovered that the less family cohesion, the more aggression and social discomfort were the most relevant risk factors, together with lower self-esteem and frequent and extreme sexual fantasies [4]. Adolescents incarcerated for sexual offenses were victims of physical or sexual abuse more often than adolescents imprisoned for other crimes.

After performing a large meta-analysis of 59 independent studies, comparing male adolescent sex offenders with male adolescent non-sex offenders, Seto et al. warned the involved professionals against the risk of explaining adolescent sex offending in an oversimplified way, as a simple manifestation of general antisocial tendencies. According to these authors, variables, such as atypical sexual interests or a sexual abuse history, could play a role more influential than criminal history, antisocial associations, and substance abuse [5].

According to other authors, there is a sort of continuum from juvenile to adult sexual offenders. Previous studies have shown that the behavior of many JSO shares similar paraphilic sexual impulses and behavioral patterns with adult sexual offenders [1].

It seems that if the adolescent has been victim of a sexual abuse, between the ages of 3 and 7 , he will probably develop pathological sexual fantasies in the late adolescence [6].

In a 2002 paper, Kubik and coworkers argued that male and female JSO are very similar with respect to psychosocial and criminal histories, antisocial behavior, level of denial about offenses, and specific sex offense behaviors [7]. Female JSO are usually younger than males, at the time of their arrest for a sex offense, and appear to choose male and female victims proportionately, whereas males are more likely to choose female victims [8]. According to Tardif, a conflict associated with 
both parents is very frequent in the history of female JSO. In the specific instance, the father is depicted as an absent and not very involved individual, whereas the mother has often a rather disturbed relationship with her daughter [9]. There is lack of research and of diagnostic tools on this category of JSO, and it is not possible to come to any definitive conclusion on the basis of the available literature [10].

This overview has reported only a minor part of the several hypotheses concerning the etiology of juvenile sex offending, and there would be many other aspects of this topic to analyze, such as the association between adolescent sex offending and autism spectrum disorders symptoms [1], the relationship between sexual offending and sex chromosome abnormality [11], or - from a psychological perspective - the effects of attachment style, interpersonal involvement, and hypersexuality in sexual perpetration against children [12].

Although, in the last decades, there has been a significant increase of experts' knowledge about this controversial topic, the reader should understand that so many questions still need to be answered. Therefore, in accordance with O'Shaughnessy's view, it could be assumed that JSO are by nature a complex and heterogeneous group and that there is no single cause or etiological agent common to all JSO subgroups. Multiple causation and the involvement of many interactive factors must be taken into consideration [13] (see also " $\triangleright$ Sexual Abuse - Current Medico-legal, Forensic and Psychiatric Aspects").

Not less problematic is the classification of youngsters who have committed sex offending. According to Underwood, a taxonomy or classification of the JSO, based on the offenses committed or characteristics of the adolescent, should guide the professionals, including mental health, medical, law enforcement, social services, and education, toward an effective pathway of treatment [14]. This author reported some of the most frequently used classification systems:

- The O'Brien and Bera's typology, according to which JSO can be categorized using an adult sex offender classification system, distinguishing seven different possible not mutually exclusive categories: (1) naïve experimenter (the main features are little history of maladaptive behavior, sexually inexperienced, sexual acts generally nonthreatening with a younger child), (2) undersocialized child exploiter (usually described as socially isolated individuals, who commit reiterated sexual offenses by means of manipulation and/or enticement), (3) pseudosocialized child exploiter (characterized by a little history of problematic behaviors, his/her attitude shows adaptation and self-confidence, with a lack of empathy which makes them very often lifelong sexual offenders), (4) sexually aggressive (the family of origin is generally abusive and dysfunctional; an intimate desire to dominate and humiliate the victim, as a sort of revenge, emerges from the violence); (5) sexual compulsive (the family of origin is generally repressive and authoritarian; sexual acts are generally repetitive and compulsive and have the purpose of alleviating anxiety); (6) disturbed impulsive (there is a history of psychological/psychiatric disorders, matched with a social dysfunction and impulsiveness); and (7) group-influenced (the adolescent has no history of psychological/psychiatric disturbances but he/she feels the effects of a dysfunctional peer group). 
- On the basis of their "knowledge and skills" and "morality and values," Sloan and Schafer developed a classification system which discriminates (1) adolescent sex offenders who understand what is considered appropriate behavior and appreciate social rules and expectations; (2) adolescent sex offenders educated in a perverse and maladaptive setting, who do not understand social rules and expectations, but desire to become a contributing member of society; (3) adolescent sex offenders who understand societal rules and expectations and the consequences of their behavior but choose to disregard them; and (4) adolescent sex offenders who are new to the system and are transitioning into one of the above listed categories.

- According to the Witt's classification system, developed as a result of a psychodiagnostic investigation, JSO could be differentiated on the basis of personality characteristics and psychological traits in four categories: (1) antisocial/impulsive, (2) unusual/isolated, (3) overcontrolled/reserved, and (4) confident/aggressive.

- Finally, Underwood reported the classification by Geradin and Thibaut, which takes into consideration six different criteria and some subcriteria for each of them: (1) age of victim (victims are peer or adult, victims are children), (2) age and gender of the offender (male adolescent, female adolescent), (3) behavioral pattern/cognitive and emotional functioning (cognitive distortions and thinking errors, lacks empathy, socially inept, lacks impulse control and assertiveness), (4) mental retardation (sex offenses only group, group committing general and sexual offenses), (5) affective and personality disorders (major depressive disorders, prevalence of conduct disorders, high rate of alcohol and substance abuse), and (6) relationship between adolescent and adult sex offending.

The above-mentioned classification systems are very useful for both clinical and research purposes. Notwithstanding that, they also received a lot of criticisms. For instance, the victim age is a widely used criterion to classify JSO. Adolescent males who commit a sexual offense against prepubescent children probably belong to a nosographical category which is different from the category the adolescents who offend against pubescent and postpubescent victims. The former group has most likely greater deficits in psychosocial functioning but is less aggressive in its sexual behavior and addresses its pathological sexual behavior against children who are also relatives [15]. Kemper pointed out that results coming from studies comparing peer offenders and child molesters, in the group of JSO, are partially limited by a great variability and inaccuracy, typified by disregarding the so-called mixed offenders (adolescents who offend both peers and children) or using equivocal and variable criteria to assign JSO to the different subgroups [16].

\section{Assessment of the Juvenile Sex Offenders}

Assessment of the adolescent sex offender represents the first step for the choice of treatment approach (see also Chap. " Clinical Neuropsychology and the Assessment of Capacity"). When assessing adolescent sex offending 
behaviors, one needs to define the biological, psychosexual, and psychosocial factors that determine the level of sexuality the offender currently possesses [17]. It is necessary to create a nonjudgmental environment when interviewing adolescent sex offenders because this will minimize the adolescent's defensiveness.

The evaluation of JSO concerns family history variables (such as history of abuse, parent-child relationship, discipline, attachment), externalizing behaviors (such as violence, delinquency), internalizing behaviors (such as depression, low self-esteem, poor coping), maladaptive sexual behaviors (such as sexual interest in children, deviant sexual fantasies), problems in social deficits (such as social skills, empathy, loneliness), and attitudinal/cognitive variables (such as attitudes toward rape, rationalizations). Information concerning demographics, family background, criminal history, social history, peer relationships, school adjustment and performance, substance abuse history, sexual history, and history of physical or sexual abuse will afford valuable insight into the level and type of treatment necessary to meet the needs of the individual offender.

The evaluation of adolescent sex offenders is based on semistructured interviews and clinical interviews and when it is requested physiological assessment.

A semistructured interview is used to gather information both from the parent and the adolescent in order to obtain the most comprehensive data about educational status, employment, alcohol, and substance abuse. It is the clinical interview that is the basis for assessing the personal characteristics of the adolescent sex offender, as well as deciphering their sexually offending behaviors.

The clinical interview will include a mental status exam, sexual-aggression history, developmental and psychosocial history, medical and psychiatric history, recommendations for psychological testing, and possible treatment interventions [17].

The mental status exam may explore the presence of psychopathology and identify environmental stressors that may contribute to the deviant behavior. The sexual-aggression history enables the psychologist to assess the adolescent's level of sexual development, knowledge, and experiences [17, 18]. The developmental and psychosocial history may determine if there is any significance between the adolescent's sex offending behavior and their ability to successfully meet developmental milestones. These developmental milestones include the ability to develop appropriate interpersonal relationships with family, peers, and friends and evaluate the influence that the family system has on their deviant sexual behavior. A medical examination is necessary in order to rule out any physiological disorder that might contribute to their maladaptive behavior. The psychiatric evaluation of JSO is important to assess any psychopathology, such as depressive or bipolar disorder, obsessive-compulsive disorder, conduct disorder, gender identity disorder, personality disorder, or substance abuse disorder. All sexual offenses in adolescents have been assessed comorbid with almost all psychiatric disorders, which make the evaluation and assessment imperative in order to establish an appropriate treatment plan [19]. For the evaluation of this particular type of population, the association between the clinical interview and a battery of psychological assessments, to 
develop a better treatment regime that is tailored to meet the adolescent sex offender's needs, is important.

The instruments commonly used for clinical assessment of the adolescent sex offenders are Children Behavioral Checklist (CBCL), the Youth Self-Report (YSR), the Child and Adolescent Functional Assessment Scale (CAFAS), the Structured Developmental History, Behavior Assessment System for Children Revised (BASC-R), Child Severity of Psychiatric Illness Assessment (CSPI), Adolescent Drinking Index (ADI), and Adolescent Drug Involvement Scale (ADIS) [20-23].

The CBCL along with the YSR may be used to assess emotional and behavioral difficulties. The CAFAS measure functioning in the following areas: school/work, home, community, behavior toward others, moods/emotions, self-harm, substance abuse, and thinking. The Structured Developmental History must be completed by the adolescent's parents to assess the reason for the adolescent sex offender's referral, family structure and background, demographics, and medical and psychosocial history. BASC-R is an adolescent and parent rating scale that measures the internalizing and externalizing problems as well as the adolescent's adaptive skills. The CSPI assesses risk behaviors, functioning, and psychiatric symptoms along with the presence of pathology associated with domains. The ADI and ADIS are used to ascertain the influence of drugs and alcohol on the adolescent's sex offending behavior. The role of alcohol consumption seems to be greater in sexual offenders against boys than in girls, and this can contribute to criminal recidivism.

Another instrument to assess the degree of sexual deviance in the most severe adolescents and older sexual offenders is the Phallometric Assessment [24]. By measuring the adolescent's penile circumference changes, in response to various sexually deviant stimuli, this instrument determines sexual preference or deviant sexual arousal. Phallometric assessment is the most popular instrument for measuring sexual arousal in adult male sex offender, but with regard to JSO, there are several ethical and empirical concerns regarding the use of this technique. Given the problems in order to use this instrument for evaluating sexual arousal of adolescent sex offenders, a number of researchers and clinicians have begun to use three alternative approaches: the Affinity computerized assessment of unobtrusively measured viewing time (VT), Affinity self-report ratings of sexual attractiveness, and a self-report sexual arousal graphing procedure.

Another important issue concerning adolescent sex offender is assessment recidivism's risk. Estimates of the risk for reoffending assist with decisions regarding many critical themes, such as the level of community access, the timing of family reunification, and the delivery of specific treatment interventions. Risk assessment must be done at two points in time: at intake, or initial visitation to the treatment provider, and on completion of treatment.

Although it appears that most adolescents who commit a sexual offense are not likely to be detected by the legal system for a sexual reoffense (and, likely, that most do not reoffend sexually), there is certainly a subgroup of adolescents at risk of reoffending sexually or violently. 
Risk assessments are used to determine the sex offender's current level of sexual aggression and to possible predict future violent or sexual behavior [25]. Risk factors for sexual reoffending were classified, by consensus between the authors, into four categories based on the following criteria: supported, promising, possible, and unlikely [26].

Risk factors were labeled "supported" only if the research was focused specifically on JSO and if the available empirical evidence was not contradictory. Supported risk factors are deviant sexual interests, prior criminal sanctions for sexual assault, past sexual offenses against two or more victims, selection of a stranger victim, lack of intimate peer relationships/social isolation, and incomplete offense-specific treatment.

Another group of risk factors of recidivism is "promising risks factors," in which empirical support for these factors is currently limited to one published follow-up study with adolescents who offend sexually. Promising risks factors are problematic parent-adolescent relationships/parental rejection and attitudes supportive of sexual offending.

A third group of risk factors of recidivism is so-called possible risk factors; given the lack of empirical support and expert clinical opinion, these factors are highly speculative. They are represented by high-stress family environment, obsessive sexual interests/sexual preoccupation, impulsivity, selection of a male victim, negative peer associations and influences, environment supporting an opportunity to reoffend, past sexual assault against a child, threats or use of excessive violence or weapons during sexual offense, indiscriminate choice of victims, unwillingness to alter deviant sexual interests/attitudes, interpersonal aggression, antisocial interpersonal orientation, and recent escalation in anger or negative effect.

There are unlikely risk factors that are those in which empirical evidences are negative at the present time. They are represented by denial of the sexual offense, lack of victim empathy, history of nonsexual crimes, penetrative sexual assaults, and offending adolescent's own history of child sexual abuse.

To evaluate risk of recidivism, there are a number of published risk assessment checklists or guidelines for adolescents who have offended sexually [27-32].

To determine the predictive accuracy of violent and sexual recidivism among sex offenders, the Violence Risk Appraisal Guide (VRAG) is commonly used, which is a tool to predict the recidivism rate among violent and mentally disordered offenders. Sex Offender Risk Appraisal Guide (SORAG) is used to evaluate past sex offenses and deviant sexual preferences.

Other measures used to predict recidivism are the Rapid Risk Assessment for Sex Offender Recidivism, the Static-99 (an adult sex offender recidivism scale), and the Psychopathy Checklist-Revised (PCL-R).

Other instruments used are Adolescent Sex Offender Assessment Protocol (J-SOAP), Estimate of Risk of Adolescent Sex Offense Recidivism (ERASOR), Adolescent (Clinical) Risk Assessment Tool of Risk for Sexual Re-Offending (J-RAT), the Interim Modified Risk Assessment Tool for Sexual Re-Offending Response to Treatment (IM-RAT), and the Structured Assessment of Violence Risk in Youth. 
The J-SOAP assesses impulsive/antisocial behavior, sexual drive/preoccupation, clinical/intervention, and community stability/adjustment. The ERASOR assesses risk factors based on sexual interests, attitudes, behavior, historical sexual assaults, psychosocial functioning, family/environmental functioning, and treatment. The J-RAT relies heavily on the responses of the adolescent during the clinical interview concerning relationships, responsibility, social skills, cognitive ability, past trauma, personal characteristics and qualities, comorbidity and past treatment response, substance abuse, antisocial behaviors, pattern of sexual offending behavior, family factors, and environmental conditions. The IM-RAT is used primarily in a residential group care treatment setting to measure the ongoing progress of the adolescent to treatment in regard to the risk of recidivism. SAVRY is designed to provide an estimate of the risk of future general violence for youth aged 12-18.

\section{Treatment of the Juvenile Sex Offender}

Almost all authors concluded that interventions for juvenile offenders may have greater efficacy than interventions for adult offenders. Gray and Pithers [33] point out that "the abundant energy and youthful resources of adolescents were believed to offer vast hope for change at later stages of growth." It is noted that the address of the international literature about adolescent sex offenders is directed to treatment and rehabilitation of this population other than punishment.

The first step is to identify the typology of the sex offender through assessment conducted by a psychologist who has specialized expertise in the field. Secondly, one needs to identify a therapeutic approach for the patient, even if there is no specific treatment approach that is acknowledged to be of "best practice."

Management of JSO requires a team approach formed by psychologists and other professionals. Some of the goals of the treatment program include accepting responsibility for behavior, identifying a pattern or cycle of sex offending behavior, learning to interrupt this cycle, exploring one's own victimization or history of abuse, learning to empathize with the victim, reducing deviant sexual arousal, developing a positive self-identity, understanding the consequences of sexual offending, exploring family issues related to offending, challenging cognitive distortions and rationalizations that support or trigger offending, developing appropriate social skills, and addressing problems with substance abuse and relapse prevention.

There are many treatment modalities as interventions for adolescent sex offenders. One can also distinguish treatment approach and treatment modality, regarding the latter there is individual therapy, group therapy, and family therapy. Similarly, "multisystemic therapy" is not a treatment approach but an eclectic collection of different therapeutic approaches.

The National Adolescent Perpetrator Network (1993) suggests that satisfactory treatment will require a minimum of 12-24 months.

As overarching goals, the program seeks to promote better mental health, improve general adjustment, and ultimately reduce recidivism. Over time, there 
has been greater focus on the interpersonal relationships these patients have with peers, with staff members, and with their families.

The National Task Force on Juvenile Sex Offending was established in 1986 and published its findings in its final report in 1993. The task force identified 22 treatment goals to be addressed in treating the adolescent sex offender. The report was emphatic in stating that the primary goal of adolescent sex offenders' treatment is community safety. These 22 treatment goals must be understood as a means to achieve the primary goal of community safety.

The list of goals is as follows:

1. Acceptance of responsibility for behavior without minimization or externalizing blame

2. Identification of pattern or cycle of abusive behavior

3. Interruption of cycle before abusive behavior occurs and control of behavior

4. Resolution of victimization in the history of the abusive youth (i.e., sexual abuse, sexual trauma, physical abuse, emotional abuse, physical abuse, abandonment, rejection, loss, etc.)

5. Development of victim awareness/empathy to a point where potential victims are seen as people rather than objects

6. Development of an internal sense of mastery and control

7. Understanding the role of sexual arousal in sexually abusive behavior, reduction of deviant sexual arousal, definition of non-abusive sexual fantasy

8. Development of positive sexual fantasy

9. Understanding the consequences of offending behavior for the self, the victim, and their families in addition to developing victim empathy

10. Identification (and remediation to the extent possible) of family issues or dysfunctions, which support or trigger offending: attachment disorders and boundary problems in families

11. Identification of cognitive distortions, irrational thinking, or thinking errors, which support or trigger offending

12. Identification and expression of feelings

13. Development of prosocial relationships with peers

14. Development of realistic levels of trust in relating to adults

15. Management of addictive/compulsive qualities contributing to reinforcement of deviancy

16. Remediation of developmental delays/development of competent psychological health skills

17. Resolutions of substance abuse and/or gang involvement

18. Reconciliation of cross-cultural issues

19. Management of concurrent psychiatric disorders

20. Remediation of skill deficits, which interfere with successful functioning

21. Development of relapse prevention strategies

22. Restitution/reparation to victims and community

Throughout the decade of the 1990s, these treatments have been reviewed, refined, and consolidated. Hunter and Lexier [34] lists the following essential components of the treatment process: 
- Establishing positive self-esteem and pride in one's cultural heritage.

- Teaching and clarifying values related to respect for self and others, and a commitment to stop interpersonal violence. The most effective programs promote a sense of healthy identity, mutual respect in male-female relationships, and a respect for cultural diversity.

- Providing sex education to give an understanding of healthy sexual behavior and to correct distorted beliefs about appropriate sexual behavior.

- Enhancing social skills to promote greater self-confidence and social competency.

- Teaching the impulse control and coping skills needed to successfully manage sexual and aggressive impulses.

- Teaching assertiveness skills and conflict resolution skills to manage anger and resolve interpersonal dispute.

- Programming designed to enhance empathy and promote a greater appreciation for the negative impact of sexual abuse on victim and their families.

- Provisions for relapse prevention. This includes teaching adolescents to understand the cycle of thoughts, feelings, and events that can trigger sexual acting out; identify environmental circumstances and thinking patterns that should be avoided because of increased risk of reoffending; and identify and practice coping and self-control skills necessary for successful behavior management.

According to Shaw [17], the most effective adolescent sex offender treatment programs usually include the following:

- Confronting the user's denial

- Decreasing deviant sexual arousal

- Facilitating the development of nondeviant sexual interests

- Promoting victim empathy

- Enhancing social and interpersonal skills

- Assisting with values clarification

- Clarifying cognitive distortions

- Teaching the adolescent to recognize the internal and external antecedents of sexual offending with appropriate intervention strategies

Hereunder are shown some treatment strategies, taken from the recent literature, for sex offenders and particularly for JSO.

For some authors, a reeducation model is an effective treatment for adolescent sex offenders because it creates an opportunity to continue interacting in a significant ongoing relationship. Through this method, the adolescent is able to develop positive coping strategies to deal with mental health issues such as attention/hyperactivity disorder, major depression, conduct disorder, and posttraumatic stress disorder.

Other authors assumed that adolescent sex offenders might benefit from social skills training as a form of treatment, given that recently they had identified significant social incompetence among JSO. Worling suggested that adolescent sexual offenders need competency in social skills, like "interpreting verbal and nonverbal cues, regulating affect, gauging intention, active listening, and encouraging reciprocity." Social skills training is based on the assumption that social skills 
are critical to sexual offense risk reduction since the adolescent will require the skills and confidence to form future healthy intimate relationships [35, 36].

The most common treatment in adult male sex offenders seems the cognitive behavioral therapy with relapse prevention [37]. In a recent study, it has been reported that the same treatment is the most effective therapy for male adolescent sex offenders [36].

Other approaches to treatment are chemical castration, aversion therapy, covert sensitization, and satiation therapy.

Chemical castration is based on the administration of the antiandrogens and hormonal agents such as medroxyprogesterone acetate (MPA), cyproterone acetate (CPA), and luteinizing hormone-releasing hormone (LHRH) agonists to reduce sexual drive and consequently inhibiting sexual behavior. This method is used in some cases in adults but in JSO cannot be utilized because of the potential to damage their still developing hypothalamic pituitary axis.

Aversion therapy, covert sensitization, and satiation therapy are behavioral techniques used to treat paraphilias. In aversion therapy, offender's deviant fantasies are followed by the aversive stimulus such as malodorous agent or an electric shock. Covert sensitization involves the verbalization of feelings and experiences that led to offending followed by a variety of negative consequences that can ensue from the offense, such as being caught and detained [38].

Satiation therapy involves the use of certain stimuli to masturbate to the extent of ejaculation [38].

One goal of treatment was to give patients the ability to combat deviant fantasies, but there was also a parallel goal of supporting and reinforcing nonabusive normal sexuality. Many patients are initially reluctant to discuss these activities, and Maletzky [39] noted that deviant sexual fantasies are likely the last fantasies to be shared by offenders in therapy. Evidence suggests this might be especially true for adolescents [40, 41].

In 2010, Worling and coworkers published a study in which he reported the results about effectiveness of specialized treatment for adolescents between 12 and 19 years who had offended sexually, in relation to the comparison group [42]. The results of the study indicate that specialized treatment for adolescents who offended sexually led to significant reductions in both sexual and nonsexual recidivism after a follow-up period that ranged from 12 to 20 years. The treatment used in this research is the Sexual Abuse: Family Education and Treatment (SAFE-T) Program, which is a specialized, community-based program that provides sexual abuse-specific assessment, treatment, consultation, and long-term support to (1) children and/or adolescents who have been sexually abused within their families and their families, (2) children with sexual behavior problems and their families, and (3) adolescents who have sexually offended and their families. Treatment at the SAFE-T Program is individualized to meet each adolescent's unique strengths and needs. Common themes include increasing insight and accountability for past offending, developing offenseprevention plans, enhancing awareness of victim impact, enhancing social relationships, reducing the impact of traumatic past events, enhancing family communication and relationships, and enhancing prosocial sexual attitudes and knowledge. 
Although it is too early in the history of research on JSO programs to render definitive conclusions about treatment effectiveness, science has made progress. Recently, researchers are beginning to evaluate their clinical models, and more rigorous study designs and statistical strategies are being used to interpret evaluation data.

\section{Part II: Medicolegal Procedures Related to Rape/Sexual Assault in the European Context}

\section{Epidemiological and Historical Aspects of Gender Violence and Sexual Abuse}

Violence against women and minors is a worldwide problem that has not yet been sufficiently acknowledged or denounced, as confirmed by the analyses and studies carried out at different levels and in different contexts [43, 44].

It has always been a recurrent phenomenon, differently considered in time according to the social and institutional contexts of reference, nowadays becoming a cultural and social concept, rooted in sexual relationships. The predominance of a specific definition of violence, in a given historical period, is the result of a "social negotiation" process by political and social institutions, which attach a meaning to violence according to how they conceive sexual relationships. For several centuries, it has remained an invisible, nameless issue, a part of the "victim's" everyday life, so much as to become "normality" in relations between sexes, causing some alarm and calling for sanctions only when it has undermined the social order or become prejudicial to the traditional codes of "honor." In the last decades, because of the greater attention and awareness of the inviolable rights of individuals, the phenomenon of sexual violence and every other form of violence against women and minors has raised, even in Europe, an increasing interest and attention of political, health, and social organizations.

The family is generally considered a secure place where people seek love, safety, and protection. The family is sometimes also a life-threatening setting, where violence is perpetrated more and more frequently, usually at the hands of men who have, or have had, a relationship based on trust, intimacy, or power with the women or children involved (fathers, mothers, boyfriends, former partners, brothers, sons). According to recent international epidemiological studies, the phenomenon of violence against women and minors develops above all within the scope of family relations, involving victims of every age and cultural level, even if in different forms and degrees, causing physical damages and severe consequences with regard to mental health.

With the current rules concerning sexual assault, these crimes are officially indictable: (1) when related to an indictable offense, kidnapping, attempted murder, grievous injury; (2) in the event of group sexual assault; (3) if the fact is committed by a public official or public service officer in the pursuance of his/her duty; (4) if the sexual assault occurs against a person who, at the time of the fact, is under the 
age of 14; (5) if the fact is committed by a parent, even if adoptive, or respective cohabitant; by the legal guardian; or by person responsible for the minor's health, education, training, surveillance, or custody purposes; and (6) if the sexual acts are committed with a person under the age of 10 .

\section{Juridical and Clinical Forensic Management}

With regard to the clinical forensic management of these types of abuse, it is well noted that the identification, diagnosis, management, and treatment of the victims who have suffered sexual abuse are complex issues, involving medical, psychological, social, and juridical aspects. This makes it crucial to involve different professional profiles and adopt a common and shareable language and method of intervention.

The diagnosis of sexual assault/abuse is indeed a complex one requiring a multidisciplinary approach. It is well known that it is rarely possible to make a diagnosis that is only medical: International literature reports that from $50 \%$ to $90 \%$ of women and minors victims of ascertained sexual abuse show nonspecific, or even normal, genital and/or anal evidence [45, 46]. Hence, the solution of many cases of alleged sexual assault requires not only specialized and thorough anatomical-clinical knowledge but also specific forensic medicine skills so as to acquire any evidence of the committed crime. The complexity of sexual assault cases inevitably requires the consequential collection of medical documentation in order to collect information on the case histories, on the description of the clothes, and on any traumatic lesion in the genital and anal areas, supplied with iconographical reproductions in order to collect biological "evidences," which is crucial in the subsequent judicial procedure as proof of the suffered violence. The collection of medical documentation must be supplied with laboratory tests and information (analyses of all possible traces detected and reported on clothes and in the genital-anal area, collection of biological secretions from the natural cavities and biological samples, in order to evidence the transmission of sexual diseases, if any) and a broad investigation involving both the physical examination of the victim, as well as a careful and detailed examination of the places, facts, every piece of evidence, if any, and their recovery.

The importance of the adequate recording and documentation of all the findings of forensic interest is further supported by the fact that the physical examination of sexual assault victims often provides very little, if nothing at all. Victims of sexual assault often referred too late to health professionals; thus, it becomes impossible to document recent traumatic lesions, if any (lacerations, ecchymoses in genital area and/or signs of physical violence perpetrated by the aggressor), or collect crucial evidence for the continuation of investigations.

The medical investigation, carried out to substantiate the suffered violence, is further complicated when physical examination results are totally negative; in those cases, the testimony of the minor plays a significant role, as it is the only evidence of the existence of a crime. The definition of abuse is quite broad and not 
necessarily associated with measurable, documentable "violence" (vis atrox), which explains why the investigation shifts its focus on the psychological-behavioral aspects. Although the testimony of the minor may constitute a useful source for the chronological recounting of the facts, it certainly cannot represent the only element supporting the investigation or the outcome of legal proceedings; through cross-examinations and investigations, facts need to be substantiated by other evidence or findings.

There are many obstacles in the evaluation of an allegation of sexual abuse especially against minors. Emotions and personal preconceptions may affect the investigation when there are few proofs and unbiased elements. Possible evaluation errors or false interpretations may depend on the following:

- Factors related to the alleged victim (age, nature of the relationship with the parents)

- Evaluation of the testimony's reliability and credibility [47]

- The ambiguous nature of the psychobehavioral indicators

- Experts' errors during the interview process that might contaminate the minor's free and spontaneous recounting [48, 49]

- The subsequent interpretation of the available data (erroneous discrimination between truth, lies, and false beliefs) [50]

The importance of a proper and professional assessment of the minor, and of his/ her statements, is supported by all main international and national scientific associations of this field. It implies methodological accuracy and scientific validity not only to assure greater adequacy and effectiveness of the interventions in alleged or actual abuse cases (scientific evidence-based methodology) but also in order to prevent many errors possibly able to heavily affect the lives of the various subjects involved in such legal proceedings despite of the "evidence," although the certainty or not of the abuse itself ([51-53]; Noto Charter update at July 7, 2002).

This is the age-old issue faced by those responsible for evaluating the testimony of a minor. In this regard, in Italy in 1996 was drafted the Noto Charter providing for the "guidelines to examine a minor in the event of sexual abuse" by an authoritative group of psychologists, criminologists, and jurists. The Noto Charter was reviewed in July 2002; with regard to international guidelines, this document includes specific indications aiming at granting the reliability of the results of technical investigations and the authenticity of the statements of the alleged victims, through the intervention of professionals adequately and specifically trained (use of methodologies and criteria acknowledged as reliable by the scientific community); it specifies also the models to be adopted to allow for the critical evaluation of results, granting the minor the best psychological support in compliance with the constitutional principles of a fair trial..

The most relevant point of this document worth mentioning is that "the psychological assessment cannot focus on the ascertainment of the facts at the core of the proceedings." This means that the information collected through the statements of the minor must help the judge understand if the minor is suitable, or not, to stand trial, but the expert's responsibility is not to ascertain the reliability of the minor's statements (exclusively in the competence of the judge) and cannot be delegated to the expert. 
The Noto Charter also provides for a series of measures enforced to safeguard the minor; above all, if the judge rules in favor of a deposition, it provides for it to take place in the most suitable settings so as to put the minor at ease and safeguard his/her emotional susceptibility. In detail, according to these guidelines, an interview with a minor requires the following:

- Interviewing with a minor at a time, moment, and place so as to safeguard, as much as possible, his/her serenity; informing the minor of his/her rights and role with regard to the ongoing procedure; allowing the minor to express his/her opinions, needs, and concerns; avoiding questions and behavior prejudicial to the spontaneity, honesty, and authenticity of the answers, without ascribing responsibilities to the minor in relation to any procedural development.

- If possible, video or at least sound recording is recommended with regard to the acquisition of the minor's statements and behavior; in order to be used in a trial, this material must be made available to the parties involved and to the judge.

- Always in the safeguard of the rights and best interest of the minor, item 11 of the document provides for the minor's psychological assistance to be entrusted to "a specialized operator who will maintain the assignment at every condition or degree of the prosecution. Such person must be someone other than the expert, and anyhow cannot interfere with investigation activities and evidence collection."

Hence, the management of alleged sexual assault victims is a complex issue that requires the contribution of interdisciplinary skills and the interaction among various specialized perspectives (gynecology, pediatrics, etc.) in order to deal with the psychological impact secondary to trauma and the strictly physical consequences of the violence itself, so as to reach, in the initial and crucial phase of evidence acquisition, a ruling of exclusion or admission of the suffered violence.

\section{Ready Reckoner}

- This chapter is divided into two parts. The first part deals with medicolegal, forensic, and psychiatric issues on sexual abuse committed by youngsters (the so-called juvenile sex offenders - JSO), with a special focus on diagnostic and therapeutic/rehabilitative strategies for JSO. In the second part, it has been performed an analysis of the legal-medicine aspects related to rape/sexual assault in a European context, namely, from the victims' point of view.

- In "Etiology and Classification of Juvenile Sex Offenses," main hypotheses about the origin of the sex offending behavior have been described. Personality disorders, such as psychopathy and early traumatizing experiences, could lead the adolescent to commit sexual offenses among other possible crimes. In addition, psychosocial factors - i.e., a poor family cohesion, aggression, and social discomfort - must be considered. Nevertheless, other authors assumed that variables, such as atypical sexual interests or a sexual abuse history, could play a role more influential than criminal history or antisociality. In the last part of the paragraph, the most frequently used classification systems of JSO have been reported. 
- The assessment of JSO is based on semistructured interviews and clinical interviews and when it is requested physiological assessment. Factors such as educational status, employment, or alcohol and substance abuse are investigated by means of semistructured interviews. The clinical interview will include a mental status exam, sexual-aggression history, developmental and psychosocial history, medical and psychiatric history, recommendations for psychological testing, and possible treatment interventions. Not less important is the evaluation of the recidivism's risk. Consensus criteria for the classification of risk factors for sexual reoffending according to four categories have been therefore reported: supported, promising, possible, and unlikely.

- The following paragraph is about treatment. Unfortunately, there is no specific treatment approach that is acknowledged to be of "best practice." Management of JSO requires a team approach formed by psychologists and other professionals. The primary goal of adolescent sex offenders' treatment is community safety. In addition, the 22 treatment goals to be addressed in treating the adolescent sex offender according to the National Task Force on Juvenile Sex Offending have been reported. Almost certainly, a reeducation model is an effective treatment for adolescent sex offenders because it creates an opportunity to continue interacting in a significant ongoing relationship.

- The last part of this chapter deals with the medicolegal procedures related to rape/sexual assault, with a special focus to the European context. Epidemiology and history of gender violence and sexual abuse have been reported, specifying some anthropological and sociological aspects.

- Finally, the juridical and clinical forensic management has been considered. The diagnosis of sexual assault/abuse requires a multidisciplinary approach and specific forensic medicine skills. Information on the case histories, on the description of the clothes, and on any traumatic lesion in the genital and anal areas must be carefully collected and, if it is possible, supplied with iconographical reproductions and laboratory tests, because the physical examination of sexual assault victims often provides very little, if nothing at all.

- The testimony of the minor may constitute a useful source for the chronological recounting of the facts, but it certainly cannot represent the only element supporting the investigation or the outcome of legal proceedings. In this regard, in Italy in 1996 was drafted the Noto Charter providing for the "guidelines to examine a minor in the event of sexual abuse" by an authoritative group of psychologists, criminologists, and jurists. It specifies the models to be adopted to allow for the critical evaluation of results, granting the minor the best psychological support in compliance with the constitutional principles of a fair trial.

\section{Cross-References}

- Evidence Collection in Cases of Sexual Assault

- Establishment of a Patient Ombudsman Scheme

- Suicide and Violence in US Colleges: Legal and Clinical Perspectives 


\section{References}

1. Hart-Kerkhoffs LA, Jansen LM, Doreleijers TA, Vermeiren R, Minderaa RB, Hartman CA. Autism spectrum disorder symptoms in juvenile suspects of sex offenses. J Clin Psychiatry. 2009;70:266-72.

2. Krischer MK, Sevecke K. Early traumatization and psychopathy in female and male juvenile offenders. Int J Law Psychiatry. 2008;31:253-62.

3. Van Wijk APH, Blokland AAJ, Duits N, Vermeiren R, Harkink J. Relating psychiatric disorder, offender and offence characteristics in a sample of adolescent sex offenders and non-sex offenders. Crim Behav Ment Health. 2007;17:15-30.

4. Smith S, Wampler R, Jones J, Reifman A. Differences in self-report measures by adolescent sex offender risk group. Int J Offender Ther Comp Criminol. 2005;49:82-106.

5. Seto MC, Lalumière ML. What is so special about male adolescent sexual offending? a review and test of explanations through met-analysis. Psychol Bull. 2010;136:526-75.

6. Grabell AS, Knight RA. Examining childhood abuse patterns and sensitive periods in juvenile Sex offenders. Sex Abuse. 2009;21:208-22.

7. Kubik EK, Hecker JE, Righthand S. Adolescent females who have sexually offended: comparison with delinquent adolescent female offenders and adolescent males who sexually offend. J Child Sex Abus. 2002;11:63-83.

8. Vandiver DM, Teske Jr R. Juvenile female and male sex offenders: a comparison of offender, victim, and judicial processing characteristics. Int $\mathrm{J}$ Offender Ther Comp Criminol. 2006;50:148-65.

9. Tardif M, Auclair N, Jacob M, Carpentier J. Sexual abuse perpetrated by adult and juvenile females: an ultimate attempt to resolve a conflict associated with maternal identity. Child Abuse Negl. 2005;29:153-67.

10. Vick J, McRoy R, Matthews BM. Young female sex offenders: assessment and treatment issues. J Child Sex Abus. 2002;11:1-24.

11. Harrison LE, Clayton-Smith J, Bailey S. Exploring the complex relationship between adolescent sexual offending and sex chromosome abnormality. Psychiatr Genet. 2001;11:5-10.

12. Miner MH, Robinson BE, Knight RA, Berg D, Romine RS, Netland J. Understanding sexual perpetration against children: effects of attachment style, interpersonal involvement, and hypersexuality. Sex Abuse. 2010;22:58-77.

13. O'Shaughnessy RJ. Violent adolescent sex offenders. Child Adolesc Psychiatr Clin N Am. 2002;11:749-65.

14. Underwood LA, Robinson SB, Mosholder E, Warren KM. Sex offender care for adolescents in secure care: critical factors and counseling strategies. Clin Psychol Rev. 2008;28: 917-32.

15. Hunter JA, Figueredo AJ, Malamuth NM, Becker JV. Juvenile sex offenders: toward the development of a typology. Sex Abuse. 2003;15:27-48.

16. Kemper TS, Kistner JA. An evaluation of classification criteria for juvenile sex offenders. Sex Abuse. 2010;22:172-90.

17. Shaw JA. Summary of the practice parameters for the assessment and treatment of children and adolescents who are sexually abusive of others. J Am Acad Child Adolesc Psychiatry. 2000;39(1):127-30.

18. Bailey S. Adolescent offenders. Forensic Psychiatr. 1997;10(6):445-53.

19. Fritz GK. The juvenile sex offender: forever a menace? Brown univ. Child and Adolescent Behavioral Letter. 2003;19:2-8.

20. Reynolds CR, Kamphaus RW. Behavior assessment for children-revised [manual]. Circle Pines: AGS Publishing; 1998.

21. Lyons JS, Libman-Mintzer LN, Kisel CL, Shallcross H. Understanding the mental health needs of children and adolescents in residential treatment. Prof Psych-Res Pr. 1998;29(6): $582-7$. 
22. Harrell AV, Wirtz PW. Screening for adolescent problem drinking: validation of a multidimensional instrument for case identification. Psychol Assessment. 1989;1:61-3.

23. Moberg DP, Hahn L. The alcohol drug involvement scale. J Adolesc Chem Depend. 1991; 2(1):75-88.

24. Marshall WL, Fernandez YM. Phallometric testing with sex offenders limits to its value. Clin Psychol Rev. 2000;20(7):807-22.

25. Harris GT, Rice ME, Quinsey VL, Lalumiere ML, Boer D, Lang C. A multisite comparison of actuarial risk instruments for sex offenders. Psychol Assessment. 2003;15(3):413-25.

26. Worling JR, Långström N. Assessment of criminal recidivism risk with adolescents who have offended sexually. Trauma Violence Abus. 2003;4(4):341-62.

27. Calder MC, Hanks H, Epps KJ. Juveniles and children who sexually abuse: a guide to risk assessment. Lyme Regis, U.K.: Russell House Publishing; 1997.

28. Epps KJ. Managing risk. In: Hoghughi MS, Bhate SR, Graham F, editors. Working with sexually abusive adolescents. London: SAGE; 1997. p. 35-51.

29. Lane S. Assessment of sexually abusive youth. In: Ryan G, Lane S, editors. Juvenile sexual offending: causes, consequences, and correction. San Francisco: Jossey-Bass; 1997. p. 219-63.

30. Perry GP, Orchard J. Assessment and treatment of adolescent sex offenders. Sarasota, FL: Professional Resource Exchange, Inc.; 1992.

31. Ross J, Loss P. Assessment of the juvenile sex offender. In: Ryan GD, Lane SL, editors. Juvenile sexual offending: causes, consequences, and correction. Lexington, MA: Lexington Books; 1991. p. 199-251.

32. Steen C, Monnette B. Treating adolescent sex offenders in the community. Springfield, IL: Charles C Thomas; 1989.

33. Gray AS, Pithers WD. Relapse prevention with sexually aggressive adolescents and children: expanding treatment and supervision. In: Barbaree HE, Marshall WL, Hudson SM, editors. The juvenile sex offender. New York: Guilford Press; 1993. p. 289-319.

34. Hunter JA, Lexier LJ. Ethical and legal issues in the assessment and treatment of juvenile sex offenders. Child Maltreat. 1998;3:339-48.

35. Worling JR. The estimate of risk of adolescent sexual offence recidivism (ERASOR): preliminary psychometric data. Sex Abuse. 2004;16:235-54.

36. Ikomi PA, Harris-Wyatt G, Doucet G, Elaine Rodney H. Treatment for juvenile who sexually offend in a southwestern state. J Child Sex Abuse. 2009;18:594-610.

37. Duwe G, Goldman RA. The impact of prison-based treatment on sex offender recidivism. Sex Abuse. 2009;21:279-307.

38. Fanniff AM, Becker JV. Specialized assessment and treatment of adolescent sex offenders. Aggress Violent Beh. 2006;11:265-82.

39. Maletzky BM. Treating the sexual offender. Newbury Park, CA: Sage; 1991.

40. Halpern CJT, Udry R, Suchindran C, Campbell B. Adolescent males' willingness to report masturbation. J Sex Res. 2000;37:327-32.

41. Smith AMA, Rosenthal DA, Reichler H. High schoolers' masturbatory practices: their relationship to sexual intercourse and personal characteristics. Psychol Rep. 1996;79:499-509.

42. Worling JR, Psych C, Litteljohn BD. 20-Year prospective follow-up study of specialized treatment for adolescents who offended sexually. Behav Sci Law. 2010;28:46-57.

43. Reza A, Mercy JA, Krug E. Epidemiology of violent deaths in the world. Inj Prev. 2002;2:104-11.

44. Finkelhor D. The international epidemiology of child sexual abuse. Child Abuse Negl. 2005;18:409-17.

45. Palmer CM, McNulty AM, D'Este C, Donovan B. Genital injuries in women reporting sexual assault. Sex Health. 2004;1:55-9.

46. Sommers MS. Defining patterns of genital injury from sexual assault: a review. Trauma Violence Abuse. 2007;8:270-80. 
47. Ceci SJ, Bruck M. The suggestibility of the child witness: a historical review and synthesis. Psychol Bull. 1993;113:403-39.

48. Berliner L, Barbieri M. The testimony of the child victim of sexual assault. J Soc Issues. 1984;40:125-37.

49. Goodman GS, Clarke-Steward A. Suggestibility in children testimony: implications for sexual abuse investigations. American Psychological Association. The suggestibility of children's recollection. Washington, DC; 1991.

50. Hershkowitz I, Fisher S, Lamb ME, Horowitz D. Improving credibility assessment in child sexual abuse allegations: the role of the NICHD investigative interview protocol. Child Abuse Negl. 2007;31:99-110.

51. Lamb ME, Orbach Y, Hershkowitz I, Esplin PW, Horowitz D. A structured forensic interview protocol improves the quality and informativeness of investigative interviews with children: a review of research using the NICHD investigative interview protocol. Child Abuse Negl. 2007;31:1201-31.

52. Bernet W, Corvin D. An evidence-based approach for estimating present and future damages from child sexual abuse. J Am Acad Psychiatry Law. 2006;34:224-30.

53. Moore J, Hudson P, Loda F. Child medical evaluation program: a statewide system for the medical and mental health evaluation of abused and neglected children. Forensic Sci Int. 1986;30:119-26.

\section{Further Reading}

American Academy Child Adolescent Psychiatry (AACAP). Practise parameters for the forensic evaluation of child and adolescent sexual abuse. J Am Acad Child Adolesc Psychiatry. 1997;36:423-42.

American Professional Society on the Abuse of Children. Guidelines for psychosocial evaluation of suspected sexual abuse in young children. Chicago, IL: American Professional Society on the Abuse of Children; 2002.

Grossin C, Sibille I, Lorin GG, Banasr A, Brion F, Durigon M. Analysis of 418 cases of sexual assault. Forensic Sci Int. 2003;131:125-30.

Ingemann-Hansen O, Sabroe S, Brink O, Knudsen Mpsych M, Vesterbye Charles A. Characteristics of victims and assaults of sexual violence - improving inquiries and prevention. J Forensic Leg Med. 2009;16:182-8.

Jonson-Reid M, Way I. Adolescent sex offenders: incidence of childhood maltreatment, serious emotional disturbance, and prior offenses. Am J Orthopsychiatry. 2001;71:120-30.

Riggs N, Houry D, Long G, Markovchick V, Feldhaus KM. Analysis of 1076 cases of sexual assault. Ann Emerg Med. 2000;35:358-62.

Saint-Martin P, Bouyssy M, O'Byrne P. Analysis of 756 cases of sexual assault in tours (France): medico legal findings and judicial outcomes. Med Sci Law. 2007;47:315-32.

World Health Organization (WHO) Global estimates of health. Consequences due to violence against children. Background paper for the United Nations study on violence against children. Geneva; 2006.

World Health Organization (WHO). Summary report multi-country study on women's health and domestic violence against women. Geneva; 2005. 